\title{
Adverse Effects of Autoclaved Diets on the Progression of Chronic Kidney Disease and Chronic Kidney Disease-Mineral Bone Disorder in Rats
}

\author{
Annabel Biruete $^{a, b}$ Shruthi Srinivasan ${ }^{a} \quad$ Kalisha D. O’Neill ${ }^{a} \quad$ Colby J. Vorland ${ }^{c, d}$ \\ Kathleen M. Hill Gallant ${ }^{\mathrm{a}, \mathrm{d}}$ Weijing Cai ${ }^{\mathrm{e}}$ Jaime Uribarrie Nancy Johnston ${ }^{f}$ \\ Matthew R. Allen ${ }^{a, b}, g$ Neal X.Chen ${ }^{a}$ Sharon M. Moe ${ }^{a, b, g}$ \\ a Division of Nephrology, Indiana University School of Medicine, Indianapolis, IN, USA; ${ }^{b}$ Department of Anatomy and

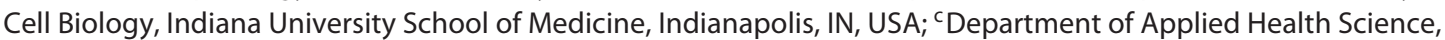 \\ School of Public Health-Bloomington, Indiana University, Bloomington, IN, USA; didepartment of Nutrition Science, \\ Purdue University, West Lafayette, IN, USA; 'Division of Nephrology, Icahn School of Medicine at Mount Sinai,

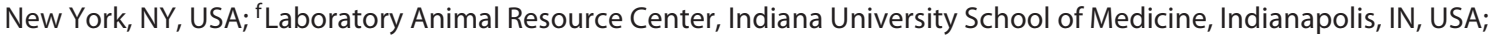 \\ ${ }^{g}$ Roudebush Veterans Affairs Medical Center, Indianapolis, IN, USA
}

\section{Keywords}

Diet · Advanced glycation end-products · Oxidative stress · Gastrointestinal · Chronic kidney disease-mineral and bone disorder

\begin{abstract}
Background: Autoclaving rodent diets is common in laboratory animals, but autoclaving increases the formation of dietary advanced glycation end-products (AGE). We studied the effect of autoclaved $(A C)$ diet alone or in combination with a diet high in bioavailable phosphorus on biochemistries of chronic kidney disease-mineral and bone disorder (CKD-MBD), intestinal gene expression, and oxidative stress. Methods: Male CKD rats (Cy/+) and normal littermates were fed 1 of 3 diets: AC $0.7 \%$ phosphorus grain-based diet for 28 weeks (AC); AC diet for 17 weeks followed by non-autoclaved (Non-AC) $0.7 \%$ phosphorus casein diet until 28 weeks (AC + Casein); or Non-AC diet for 16 weeks followed by a Non-AC purified diet until 30 weeks (Non-AC + Casein). Results: AC diets contained $\sim 3 \times$ higher AGEs and levels varied depending on the location within the autoclave. Rats fed the AC and
\end{abstract}

(c) 2020 S. Karger AG, Basel

\section{karger@karger.com}

www.karger.com/ajn
AC + Casein diets had higher total AGEs and oxidative stress, irrespective of kidney function. Kidney function was more severely compromised in CKD rats fed $A C$ or $A C+$ Casein compared to Non-AC + Casein. There was a disease-by-diet interaction for plasma phosphorus, parathyroid hormone, and c-terminal fibroblast growth factor-23, driven by high values in the CKD rats fed the $A C+$ Casein diet. Compared to Non-AC + Casein, AC and AC + Casein-fed groups had increased expression of receptor of AGEs and intestinal NADPH oxidase dual oxidase-2, independent of kidney function. Conclusions: Autoclaving rodent diets impacts the progression of CKD and CKD-MBD, highlighting the critical importance of standardizing diets in experiments.

(c) 2020 S. Karger AG, Basel

\section{Introduction}

Diet influences chronic kidney disease (CKD) and CKD-mineral and bone disorder (CKD-MBD) [1]. Traditional rodent diet is grain-based, which varies widely in grain source, quantity, and bioavailability of phosphorus 
due to differences in grain and soil phosphate content [2]. In contrast, purified diets using casein as a protein source are standardized in protein content and the phosphate is more bioavailable, behaving similar to phosphate additives consumed by humans. In our model of progressive $\mathrm{CKD}$, the $\mathrm{Cy} /+$ rat, we have fed rats a grain-based diet until 24 weeks of age, then change to a casein-based diet (0.7\% phosphorus) to provide standard phosphate bioavailability, yielding a more consistent time course for the development of CKD-MBD [3, 4]. However, we recently noted a faster decline in kidney function and expedited development of CKD-MBD in our rat colony, coinciding with the initiation of a policy of autoclaving all standard grain-based diets used in our animal facility.

The use of autoclaved (AC) diet rodent diets has been increasing in research animal facilities to reduce foodrelated infections transmitted through the use of grainbased byproducts $[5,6]$. In contrast, purified diets are not sterilized after production, and the only heat processing they undergo is extrusion for the creation of the food pellets. The protocol for autoclaving rodent feeds is similar to experimental protocols utilized to purposefully increase the dietary content of advanced glycation endproducts (AGE): $100^{\circ} \mathrm{C} \times 20-60 \mathrm{~s}$ and $125^{\circ} \mathrm{C} \times 20-30 \mathrm{~min}$ [7]. We therefore tested the hypothesis that the accelerated CKD and CKD-MBD in our Cy/+ model was due to the increase in dietary AGEs as a result of autoclaving.

\section{Methods}

\section{Animals}

Male heterozygous rats $\left(\mathrm{Cy} /+_{\mathrm{IU}}\right.$; $\mathrm{CKD}$ rats hereafter $)$, derived from the colony at Indiana University, develop characteristics of CKD around 10 weeks of age and have progressive loss of kidney function and the 3 characteristics of CKD-MBD: biochemical abnormalities, bone alterations, and aortic calcification [3]. Male CKD rats and their normal littermates (NL) were used. All procedures were approved by the Indiana University School of Medicine and Purdue University Institutional Animal Care and Use Committees.

Experimental Design (online Suppl. Fig. 1; for all online suppl. material, see www.karger.com/doi/10.1159/000506729)

Three groups of rats all derived from the same colony over the course of 1 year and studied concurrently were differentially exposed to an AC (Envigo Teklad Global 2018SX), non-autoclaved (NonAC) grain-based diets (Envigo Teklad 2018), or a purified custom casein diet with $0.7 \%$ phosphorus and $15.9 \%$ percent protein. Composition of the diets is in online supplementary Table 1. CKD and NL were given 3 different diets ( $n=8-11$ rats per group): (1) AC group: AC grain diet from birth to 28 week, studied at Indiana, (2) AC + Casein group: AC grain diet until 17 weeks then casein diet until 28 weeks, studied at Indiana, (3) Non-AC + Casein group: Non-AC grain from birth to 16 weeks then switched to casein diet until 30 week of age, studied at Purdue [8]. All groups had access to water and food ad libitum light-dark cycle from 6 a.m. to 6 p.m. At the end of the studies, rats were anesthetized with isoflurane, the thoracic cavity was opened, blood collected from the vena cava resulting in death, and intestinal tissues were collected (online suppl. Table 2).

\section{Dietary Content of AGEs}

Protein-linked carboxymethyllysine (CML) and methylglyoxal (MG) were determined in the grain-based diet according to the position in the autoclave used in our research animal facility (Getinge Sterilizer, Wayne, NJ, USA). Teklad 2018SX diet was sterilized in racks with 6-7 33lb bags of food for 5 min exposure time, $20 \mathrm{~min}$ exhaust time at $121^{\circ} \mathrm{C}$. Random samples were taken from all feed bags in autoclave as shown in Figure 1. CML and MG were determined according to Goldberg et al. [9] via ELISA. The results were expressed as CML and MG per mg/protein.

\section{Plasma Biochemistries}

Plasma creatinine, blood urea nitrogen (BUN), calcium, and phosphorus were determined by quantitative colorimetric assay (creatinine: Quantichrom DICT-500; BUN: Quantichrom urea assay kit; calcium and phosphorus: Pointe Scientific Inc.); fibroblast growth factor-23 (FGF23; intact and c-terminal), intact parathyroid hormone (PTH), 8-hydroxy-2'-deoxyguanosine (8OHdG; a marker of DNA oxidative damage), and total AGEs were measured by ELISA (intact and c-terminal FGF23 and intact PTH: Immutopics, Inc.; 8OHdG: Enzo Life Sciences; AGEs: OxiSelect AGEs kit, Cell Biolabs, Inc.). All plasma biochemistries were performed at Indiana.

\section{Intestinal Gene Expression}

For the AC and AC + Casein groups, at 28 weeks, duodenum and jejunum were dissected according to Moe et al. [4] and for the Non-AC + Casein according to Vorland et al. [8]. Tissues were flushed with $0.9 \%$ saline using a gavage needle to remove luminal contents, cut transversally with scissors, the mucosa scraped with microscope cover slip, and the tissue placed in a microcentrifuge tube and flash-frozen with liquid nitrogen.

For the AC and AC + Casein groups, total RNA was isolated at Indiana using miRNeasy Mini Kit (Qiagen) and the Non-AC + Casein groups at Purdue using Omega HP Total RNA Kit (R6812-00, Omega Bio-tek, Norcross, GA, USA) according to manufacturer's instructions. All real-time PCR was performed at Indiana using TaqMan gene expression assays with Applied biosystems ViiA 7 Real-Time-PCR Systems: NaPi2b (Slc34a2; Rn00584515_m1), PiT1 (Slc20a1; Rn00579811_m1), receptor of AGEs (RAGE; Ager; Rn01525753_g1), NADPH-oxidase 2 (NOX2; Cybb; Rn00576710_ $\mathrm{m} 1$ ), dual oxidase-2 (DUOX2; Rn00666512_m1), and $\beta$-actin (Actb; Rn00667869_m1). The $\Delta \Delta \mathrm{CT}$ method was used to analyze the relative change in gene expression normalized to $\beta$-actin.

\section{Statistical Analyses}

Each rat represented an experimental unit within a group (NL or CKD) with a treatment (diet). All outcomes were assessed for normality and variance using Brown-Forsythe's test and log-transformed before analyses as appropriate. Outliers were assessed and removed (range $0-5$ per group in each assay) before analysis by the ROUT method based on the False Discovery Rate (Q) of 1\% [10]. Two-way ANOVA was performed for all outcomes, where the main effects of disease (NL/CKD), diet (AC, AC + Casein, and Non-AC + Casein), and their interaction were assessed utilizing 
Fig. 1. Autoclaving grain-based diet increases CML and MG and leads to increased plasma total AGEs and oxidative stress in rats. a Standard diets were assessed for CML and MG by ELISA depending on the place in the rack where the diets are AC. b Fold difference compared to the CML and MG concentration of the Non-AC standard diet. c Total plasma AGEs were higher in rats fed the $\mathrm{AC}$ and $\mathrm{AC}+$ Casein diets than the rats fed the Non-AC + Casein diet. d There was disease-by-diet interaction in plasma $8 \mathrm{OHdG}$, a marker of oxidative stress, where $8 \mathrm{OHdG}$ was higher in $\mathrm{CKD}$ rats fed the $\mathrm{AC}$ and $\mathrm{AC}+$ Casein diets compared to NL, but not in the Non-AC + Casein rats. Within the CKD rats, those fed the $\mathrm{AC}$ and $\mathrm{AC}+$ Casein had higher concentrations than the Non-AC + Casein CKD rats. ${ }^{* *} p<0.01,{ }^{* * *} p<0.001$. CML, carboxymethyllysine; MG, methylglyoxal; AGEs, advanced glycation end-products; AC, autoclaved; Non-AC, non-autoclaved; 8OHdG, 8-hydroxy-2'-deoxyguanosine; CKD, chronic kidney disease; NL, normal kidney function.

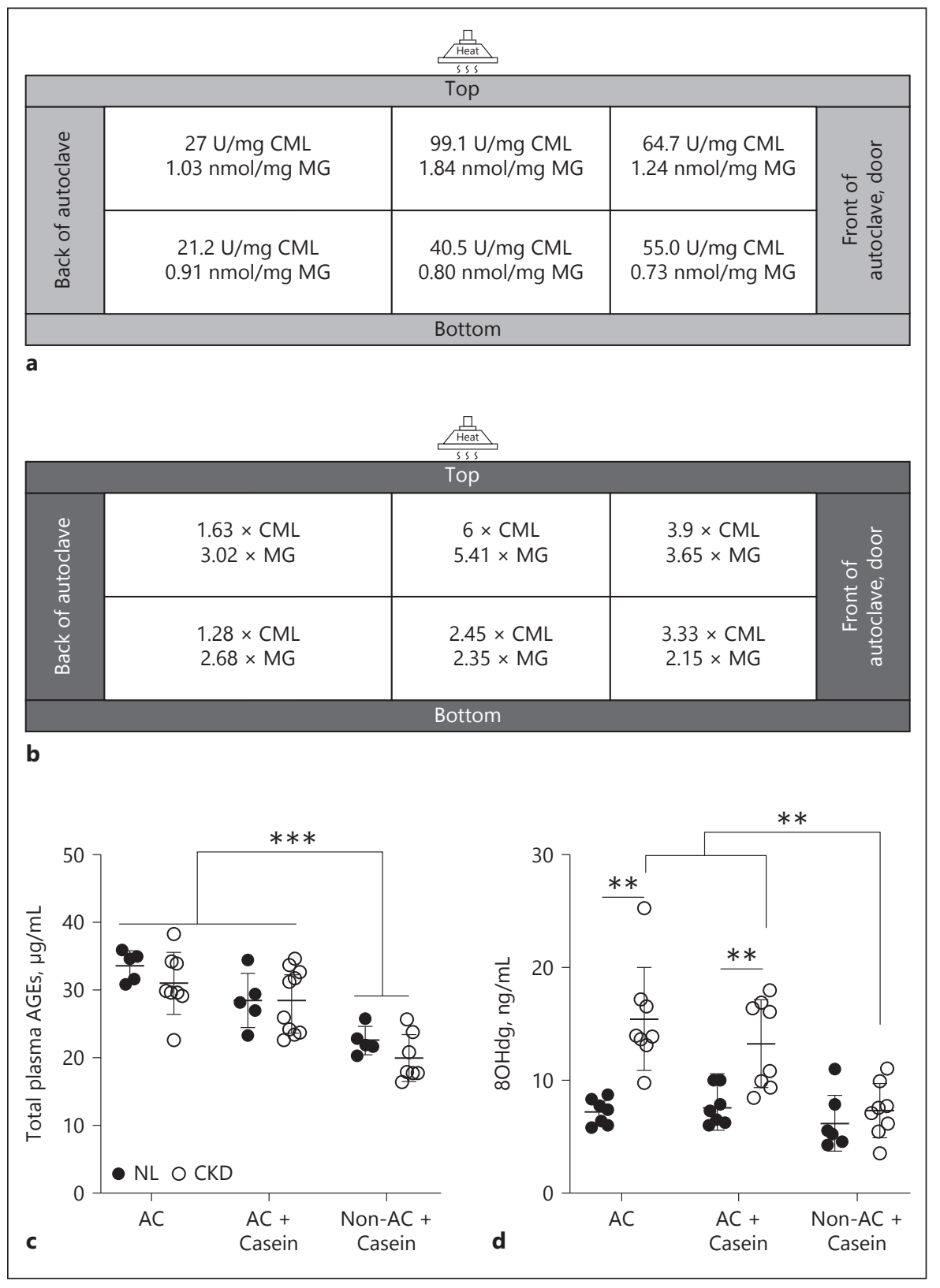

least-squares means with Tukey post hoc comparisons. Statistical significance was set at $a<0.05$. All statistical analyses were performed in GraphPad Prism 8.2.0 (San Diego, CA, USA). Results are reported as mean \pm SD unless otherwise noted.

\section{Results}

\section{AGE Content in Animal Diets}

AC diet contained $\sim 2.8 \times$ higher $\mathrm{CML}$ than the Non-AC diet, while MG was $\sim 3.2 \times$ higher (Fig. 1a). The CML con- tent in the casein diet was similar to the Non-AC diet, while MG was $\sim 1.8 \times$ higher in the casein diet versus the Non-AC diet (Fig. 1b). The CML and MG content was affected by the position of the diet bag in the autoclave (Fig. 1a, b). The highest AGE content feed was from bags in the middle-top rack of the autoclave, corresponding to the location closest to the heat source, while the lowest amount of CML was found in the bags positioned at the back of the autoclave (top and bottom racks). The lowest concentration of $\mathrm{MG}$ was in the front-bottom rack of the autoclave, while the highest was in the middle-top rack of the autoclave. 
Table 1. Final plasma biochemistries and intestinal gene expression

\begin{tabular}{|c|c|c|c|c|c|c|c|c|c|}
\hline & \multicolumn{2}{|l|}{$\mathrm{AC}$} & \multicolumn{2}{|l|}{$\mathrm{AC}+$ Casein } & \multicolumn{2}{|l|}{ Non-AC + Casein } & \multirow[t]{2}{*}{ Disease } & \multirow[t]{2}{*}{ Diet } & \multirow[t]{2}{*}{ Interaction } \\
\hline & NL & CKD & NL & CKD & NL & CKD & & & \\
\hline \multicolumn{10}{|l|}{ Plasma biochemistries } \\
\hline Creatinine, $\mathrm{mg} / \mathrm{dL}$ & $0.48 \pm 0.03(7)$ & $1.26 \pm 0.24(10)$ & $0.52 \pm 0.22(6)$ & $0.98 \pm 0.30(11)$ & $0.46 \pm 0.10(9)$ & $0.80 \pm 0.19(9)$ & $<0.001$ & 0.0393 & 0.0387 \\
\hline $\mathrm{BUN}, \mathrm{mg} / \mathrm{dL}$ & $21.23 \pm 2.25(8)$ & $47.35 \pm 2.36(10)$ & $21.30 \pm 2.84(8)$ & $49.12 \pm 6.25(11)$ & $15.60 \pm 1.60(10)$ & $38.78 \pm 4.78(9)$ & $<0.001$ & $<0.001$ & 0.1847 \\
\hline Calcium, mg/dL & $6.26 \pm 0.69(8)$ & $6.49 \pm 0.73(10)$ & $6.83 \pm 1.05(8)$ & $8.14 \pm 1.51(10)$ & $5.88 \pm 0.98(10)$ & $5.95 \pm 1.41(9)$ & 0.0797 & $<0.001$ & 0.2021 \\
\hline Phosphorus, mg/dL & $4.79 \pm 0.53(8)$ & $5.96 \pm 0.43(10)$ & $5.67 \pm 1.03(7)$ & $9.66 \pm 4.19(11)$ & $5.62 \pm 1.40(10)$ & $5.92 \pm 1.07(9)$ & $<0.001$ & 0.002 & 0.0430 \\
\hline $\mathrm{iPTH}, \mathrm{pg} / \mathrm{mL}$ & $93.65 \pm 17.05(8)$ & $357.9 \pm 154.7(10)$ & $135.0 \pm 42.95(7)$ & $2,005 \pm 1,631.3(11)$ & $852.4 \pm 295.9(10)$ & $1,471 \pm 582.8(8)$ & $<0.001$ & $<0.001$ & $<0.001$ \\
\hline $\mathrm{iFGF} 23, \mathrm{pg} / \mathrm{mL}$ & $539.6 \pm 64.84(5)$ & $2,291 \pm 1,186(10)$ & $715.9 \pm 152.0(6)$ & $3,038 \pm 979.4(9)$ & $492.0 \pm 57.15(10)$ & $1,870 \pm 437.3(9)$ & $<0.001$ & $<0.001$ & 0.2841 \\
\hline c-terminal FGF23, pg/mL & $290.9 \pm 56.27(7)$ & $1,720 \pm 771.7(10)$ & $434.5 \pm 124.5(8)$ & $2,683 \pm 1,290.5(8)$ & $531.8 \pm 124.8(7)$ & $1,625 \pm 689.4(8)$ & $<0.001$ & 0.0064 & 0.0117 \\
\hline Total AGEs, $\mu \mathrm{g} / \mathrm{mL}$ & $33.52 \pm 2.19(5)$ & $30.91 \pm 4.62(8)$ & $28.39 \pm 4.00(5)$ & $28.36 \pm 4.78(10)$ & $22.49 \pm 2.03(5)$ & $19.95 \pm 3.50(7)$ & 0.1894 & $<0.001$ & 0.6418 \\
\hline $8 \mathrm{OHdG}, \mathrm{ng} / \mathrm{mL}$ & $7.18 \pm 1.15(7)$ & $15.41 \pm 4.55(8)$ & $7.55 \pm 1.64(8)$ & $13.23 \pm 3.90(8)$ & $6.17 \pm 2.46(7)$ & $7.33 \pm 2.39(8)$ & $<0.001$ & $<0.001$ & 0.0317 \\
\hline \multicolumn{10}{|c|}{ Duodenum and jejunum gene expression } \\
\hline Jejunum NaPi2b & $0.72 \pm 0.42(7)$ & $0.52 \pm 0.28(8)$ & $0.58 \pm 0.44(8)$ & $0.48 \pm 0.57(11)$ & $0.70 \pm 0.17(9)$ & $0.67 \pm 0.19(8)$ & 0.3676 & 0.0484 & 0.8330 \\
\hline Jejunum PiT1 & $0.70 \pm 0.43(8)$ & $0.75 \pm 0.28(10)$ & $0.32 \pm 0.13(7)$ & $0.61 \pm 0.35(11)$ & $0.68 \pm 0.14(9)$ & $0.80 \pm 0.19(8)$ & 0.0534 & 0.0110 & 0.4380 \\
\hline Duodenum RAGE & $1.34 \pm 0.22(7)$ & $1.83 \pm 0.70(10)$ & $2.00 \pm 0.73(8)$ & $2.34 \pm 1.56(10)$ & $0.17 \pm 0.02(9)$ & $0.14 \pm 0.06(9)$ & 0.2341 & $<0.001$ & 0.6227 \\
\hline Jejunum RAGE & $1.57 \pm 0.70(8)$ & $1.502 \pm 0.61(9)$ & $3.34 \pm 1.06(8)$ & $3.18 \pm 1.66(11)$ & $0.17 \pm 0.06(10)$ & $0.19 \pm 0.09(9)$ & 0.7867 & $<0.001$ & 0.9575 \\
\hline Duodenum NOX2 & $1.79 \pm 1.19(6)$ & $1.65 \pm 0.69(9)$ & $2.38 \pm 1.18(7)$ & $3.19 \pm 2.05(10)$ & $7.97 \pm 1.17(8)$ & $6.54 \pm 2.86(9)$ & 0.6243 & $<0.001$ & 0.1876 \\
\hline Jejunum NOX2 & $2.74 \pm 1.56(7)$ & $2.12 \pm 0.64(9)$ & $7.39 \pm 6.93(7)$ & $3.50 \pm 1.91(10)$ & $16.15 \pm 6.78(10)$ & $13.84 \pm 4.76(9)$ & 0.0505 & $<0.001$ & 0.3718 \\
\hline Duodenum DUOX2 & $2.13 \pm 1.51(7)$ & $1.91 \pm 1.69(9)$ & $2.20 \pm 1.38(7)$ & $1.24 \pm 0.35(5)$ & $0.33 \pm 0.30(7)$ & $0.40 \pm 0.32(7)$ & 0.6290 & $<0.001$ & 0.5532 \\
\hline Jejunum DUOX2 & $28.13 \pm 43.60(7)$ & $11.10 \pm 5.46(8)$ & $10.15 \pm 6.98(8)$ & $32.46 \pm 40.73(11)$ & $0.55 \pm 0.24(10)$ & $0.95 \pm 0.48(8)$ & 0.7987 & $<0.001$ & 0.4671 \\
\hline
\end{tabular}

Data presented as mean $\pm \operatorname{SD}(n)$.

All gene expression was normalized using $\beta$-actin as housekeeping gene. Bold depicts statistical significance $(p<0.05)$.

AC, autoclaved; Non-AC, non-autoclaved; NL, normal littermates; CKD, chronic kidney disease; BUN, blood urea nitrogen; iPTH, intact parathyroid hormone; iFGF23, intact fibroblast growth factor-23; AGE, advanced glycation end product; $8 \mathrm{OHdG}$, 8-hydroxy-2'-deoxyguanosine; NaPi2b, sodium-dependent phosphate transporter 2b; PiT1, type III phosphate transporter 1; RAGE, receptor for AGE; NOX2, NADPH-oxidase 2; DUOX2, dual NADPH oxidase 2.

\section{Systemic Effects of AC Diets}

There was a diet effect on the total plasma AGEs concentration at 28 weeks, where the animals fed the AC and $\mathrm{AC}+$ Casein had higher values than the rats fed the Non$\mathrm{AC}+$ Casein. Post hoc testing revealed that the rats fed the AC diet had numerically higher total AGEs than the rats fed the $\mathrm{AC}+$ Casein diet, though this was not significant ( $p=0.055$; Table 1; Fig. 1$)$.

We observed a disease-by-diet interaction on plasma levels of $8 \mathrm{OHdG}$, a proxy of oxidative stress; it was higher in the CKD rats fed the $\mathrm{AC}$ or $\mathrm{AC}+$ Casein diets compared to CKD rats fed the Non-AC + Casein diet, but there was no difference between NL and CKD rats in the Non-AC + Casein groups. Within the CKD rats, plasma $8 \mathrm{OHdG}$ was higher in those fed the AC and AC + Casein diets than the Non-AC + Casein diet (Table 1; Fig. 1).

\section{Kidney Function and CKD-MBD}

Kidney function measures are reported in Table 1 and Figure 2. There was a disease-by-diet interaction in plasma creatinine. CKD rats had higher levels of plasma BUN and creatinine than NLs. Among CKD rats, plasma BUN and creatinine were not different in the $\mathrm{AC}$ and $\mathrm{AC}+\mathrm{Ca}-$ sein diets, but both were higher than the CKD Non-AC + Casein.
Biochemical measures of CKD-MBD are shown in Table 1 and Figure 2. There was a disease-by-diet interaction on plasma phosphorus, PTH, and c-terminal FGF23 driven by the CKD rats fed the $\mathrm{AC}+$ Casein diet. For intact FGF23, there were disease and diet main effects, where $\mathrm{CKD}$ rats had higher concentrations and those rats fed the $\mathrm{AC}+$ Casein diet had higher levels than AC and Non-AC + Casein, but AC and Non-AC + Casein were not different.

\section{Intestinal Gene Expression}

There was a diet effect for gene expression of the phosphorus transporters NaPi2b and PiT1 (Table 1). Jejunum $\mathrm{NaPi} 2 \mathrm{~b}$ expression was higher in the rats fed the Non$\mathrm{AC}+$ Casein than the AC + Casein-fed rats, but not different than the AC-fed rats. Jejunum PiT1 expression was lower in the rats fed the $\mathrm{AC}+$ Casein-fed rats than the $\mathrm{AC}$ and Non-AC + Casein-fed rats.

We also examined if feeding a diet high in dietary AGEs affected the intestinal expression of RAGE. We found a diet effect on RAGE expression in the duodenum and jejunum. In the duodenum, rats fed the $\mathrm{AC}$ and $\mathrm{AC}$ + Casein had higher RAGE expression than the Non-AC + Casein. However, in the jejunum, animals fed the AC + Casein diet had the highest RAGE expression (Table 1; Fig. 3). We next assessed if the higher expression of intes- 


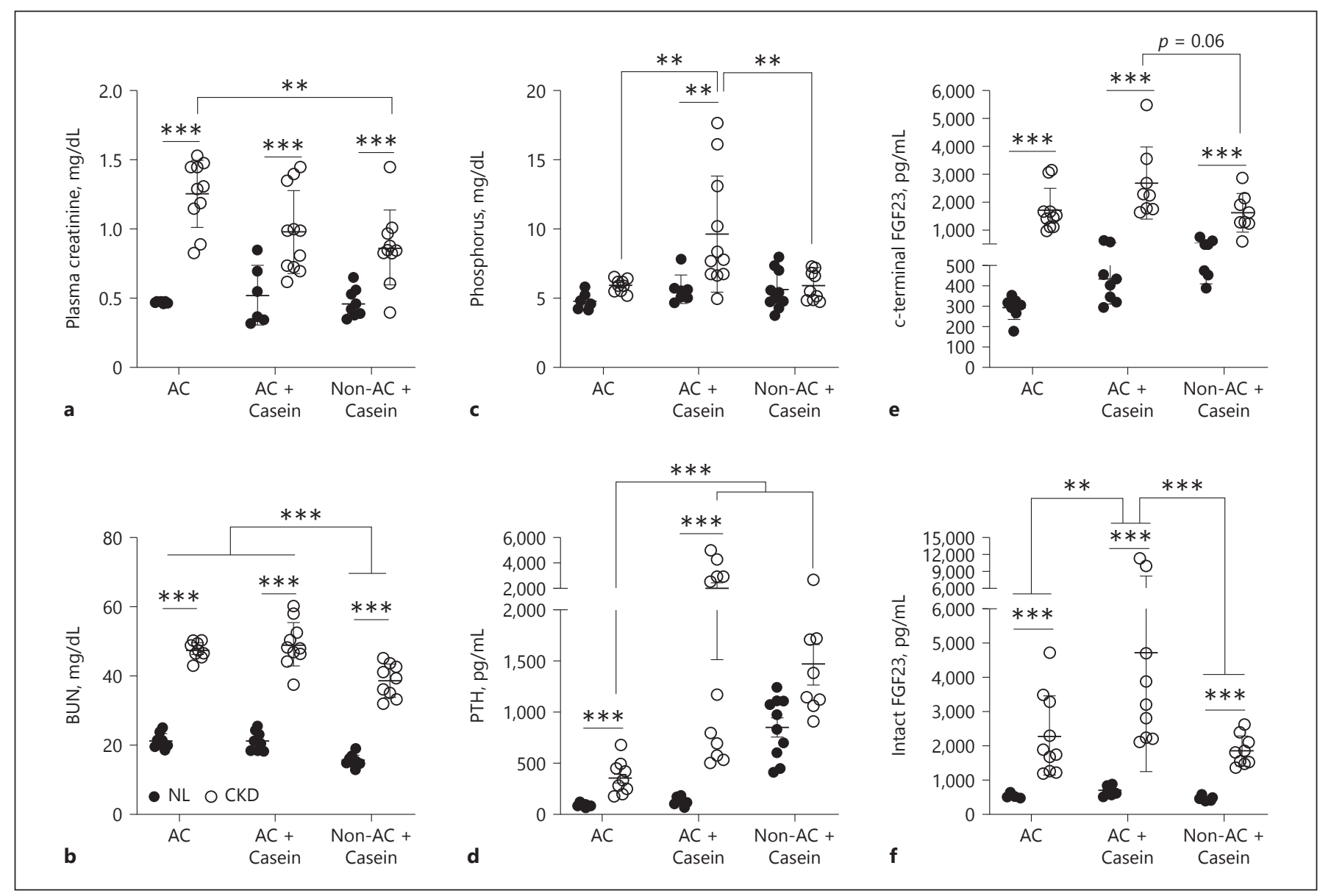

Fig. 2. Feeding an AC diet in combination with a diet high in bioavailable phosphorus worsens kidney function and biochemical parameters of CKD-MBD. a There was a disease-by-diet interaction on plasma creatinine, where the plasma creatinine was higher in the CKD rats. CKD rats fed the AC diet had higher plasma creatinine than the $\mathrm{CKD}$ rats fed the Non-AC + Casein, but not the $\mathrm{AC}+$ Casein diet. $\mathbf{b} \mathrm{BUN}$ was higher in the CKD rats across all diet groups compared to NL. BUN was higher in the rats fed the AC and AC + Casein compared to the Non-AC + Casein. c There was a disease-by-diet interaction driven by the high phosphorus levels in the $\mathrm{CKD}$ rats fed the $\mathrm{AC}+$ Casein diet. Plasma phosphorus was only different between NL and CKD rats fed the AC + Casein diet. d There was an interaction between kidney function and diet in plasma PTH, where there was a difference between the NL and $\mathrm{CKD}$ rats only in those fed the $\mathrm{AC}$ and $\mathrm{AC}+$ Casein diets, but not

tinal RAGE was associated with downstream changes in NADPH-oxidases (NOX2 and DUOX2). We observed the highest expression of jejunum NOX2 in the rats fed the Non-AC + Casein diet. There was also an effect of diet on duodenum and jejunum DUOX2 expression where the highest expression was in the animals fed the $\mathrm{AC}$ and $\mathrm{AC}+$ Casein diets.

AC Diets in Experimental CKD the Non-AC + Casein. Among the CKD rats, $\mathrm{PTH}$ was higher in the rats fed the AC + Casein and Non-AC + Casein compared to the $\mathrm{CKD}$ rats fed the $\mathrm{AC}$ diet. e There was an interaction between kidney function and diet in plasma c-terminal FGF23, where CKD rats had higher concentrations than the NL rats for all diet groups. Among the CKD rats, there were no differences between diets, but the $\mathrm{CKD}$ rats fed the $\mathrm{AC}+$ Casein diet tended to have higher concentrations than the Non-AC + Casein $(p=0.06)$. $f$ CKD rats had higher intact FGF23 than NL. Within the CKD rats, those fed the $\mathrm{AC}+$ Casein had the highest concentrations compared to AC and Non-AC + Casein. ${ }^{* *} p<0.01,{ }^{* * *} p<0.001$. AC, autoclaved; NonAC, non-autoclaved; FGF23, fibroblast growth factor-23; BUN, blood urea nitrogen; PTH, parathyroid hormone; CKD, chronic kidney disease; NL, normal littermate.

\section{Discussion}

Diet is an important variable in experimental studies. We previously found marked differences in CKD-MBD with grain versus casein diets [3], and this study further compares AC grain-based diets versus Non-AC grainbased diets. The administration of AC diet to our rat 
Fig. 3. Feeding an AC diet leads to higher expression of intestinal RAGE and the NADPH-oxidase DUOX2 in a rat model of CKD-MBD. a Duodenum RAGE expression was higher in the rats fed the $A C$ and $\mathrm{AC}+$ Casein diets. b Jejunum RAGE expression was higher in the rats fed the $\mathrm{AC}+$ Casein diet and the $\mathrm{AC}$ rats had a higher expression than the Non-AC + Casein rats. c Duodenum DUOX2 expression was higher in the AC and AC + Casein rats. $\mathbf{d}$ Jejunum DUOX2 expression was higher in the $\mathrm{AC}$ and $\mathrm{AC}+$ Casein rats. ${ }^{* *} p<0.01$, $* * * \quad p<0.001$. AGE, advanced glycation end-product; AC, autoclaved; Non-AC, non-autoclaved; RAGE, receptor for AGEs; DUOX2, dual oxidase-2; CKD, chronic kidney disease; NL, normal littermate.

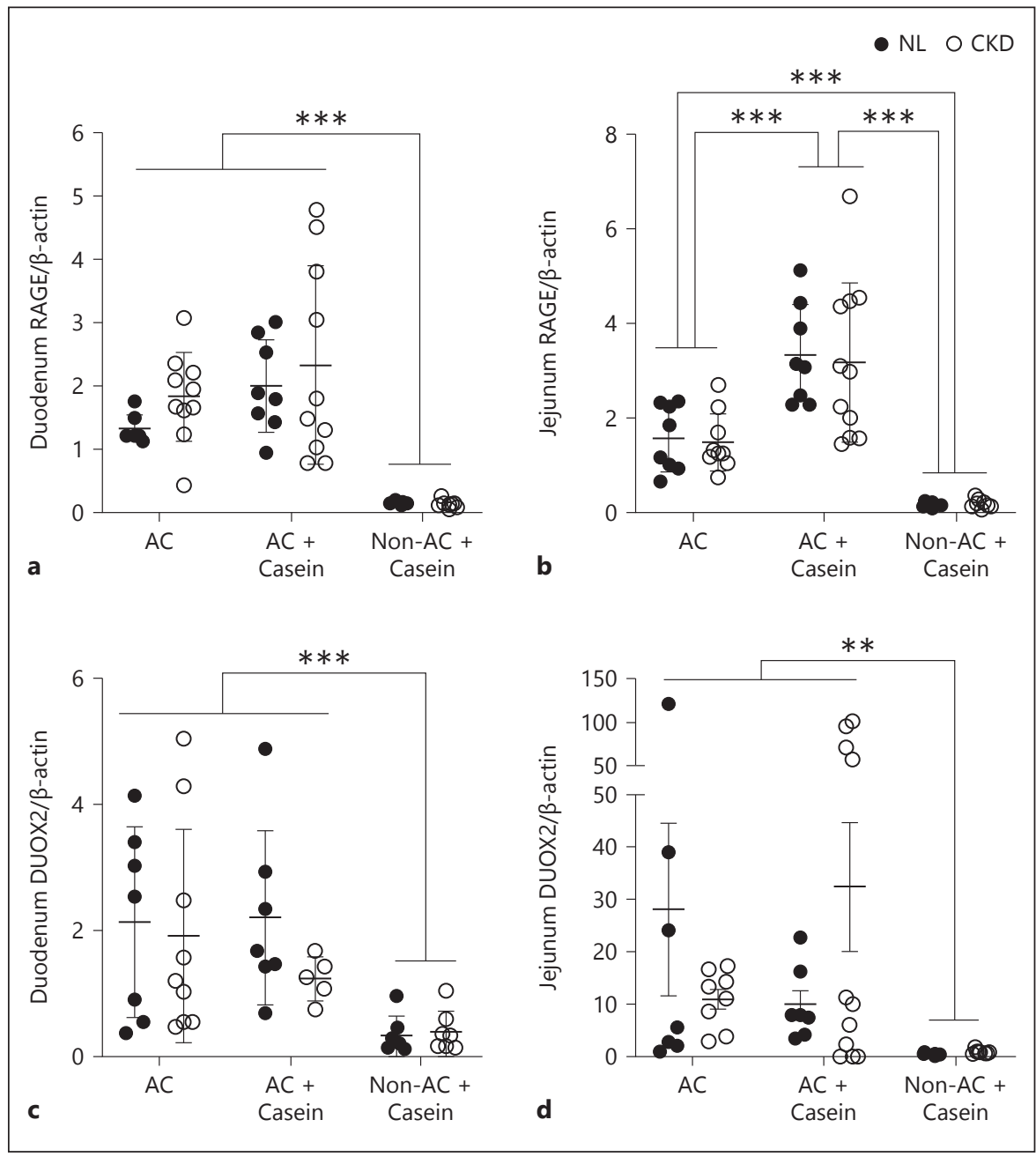

model accelerated the course of CKD and CKD-MBD and was additive to that of a casein diet. In general, compared to our previous studies, the AC diet accelerated the time course to near end-stage kidney disease by approximately 1 month, likely related to increased dietary AGE content in the AC diet, although this was not definitively proven in the current experiments. A standard autoclave protocol for sterilizing grain-based diets increased the concentration of the commonly assessed AGEs, CML, and the dicarbonyl precursor of AGEs, MG. It should be noted that the CML and MG content of the Non-AC diets was not zero, as all pelleted food undergoes extrusion and drying with heat and this may set a "baseline" dietary AGE concentration [11]. Importantly, we found that the higher dietary AGEs concentration varied depending on the location within the autoclave, where the highest concentrations of CML and MG were found near the heat source in the autoclave. Thus, it may be impossible to standardize the quantity of dietary AGEs provided to each experimental animal as experimental animals receive food from AC bags in a random fashion.

The use of AC feeds has been increasing as a way to reduce infections, particularly parvovirus [12]. This practice was recommended for sterilized feeds at the 2009 National American Association for Laboratory Science meeting. Standardization and control of variables are important to maximize reproducibility in experimental studies. The Animal Research: Reporting of In Vivo Experiments guidelines were developed to help researchers know the amount of information that should be reported in published studies to maximize reproducibility [13]. In the Housing and Husbandry section of the guidelines, type of food is listed as a variable, but the guidance does not give specific characteristics of the diet to be included. Unfortunately, in scientific publications, diet is often vaguely reported, particularly in studies where the effect of diet is not being evaluated. The 
content of purified diets is tightly controlled, whereas grainbased diets vary considerably due to nonstandardization of grain used, batch-to-batch variability, and seasonal variability depending on the crop harvest [14]. For example, 1 year (or part of a year) the standard grain-based diet may be predominately corn-based, whereas in another year wheat-based [14]. Whether or not the diet was AC is seldom reported.

Although we did not specifically investigate the variation of grain-based versus purified diets, these can also vary widely in the source of macronutrients, exemplified in online supplementary Table 1 . These nutrient factors include carbohydrate source, fatty acid composition, source of protein, and dietary fiber. Dietary fiber, for example, has gained importance as it can influence intestinal health and the gut microbiome in rodent models [15]. In most experimental studies investigating CKD-MBD, nutrients such as phosphorus and calcium are reported, while others are often ignored. This means that modification of nutrient bioavailability and the amount of AGEs is often not known.

In our study, the plasma total AGE concentration was different depending on the diet the rats were fed, with the highest concentration in the AC, followed by the AC+ Casein, and the lowest concentrations were in the Non$\mathrm{AC}+$ Casein. This highlights the possible contribution of dietary sources of AGEs to the circulating levels of AGEs. Dietary AGEs absorption has been reported to be $10-30 \%$ [16]. However, only 30\% of the dietary AGEs that are absorbed are excreted in urine. Thus, a significant portion is retained [16]. In normal kidney function, circulating AGEs are filtered in the glomeruli and then reabsorbed in the tubules, with some tubular secretion possible [17]. As a result, the kidneys are one of the tissues with the highest AGE accumulation when diseased, including in diabetic and nondiabetic models of CKD $[18,19]$. In the current study, we also found that plasma $8 \mathrm{OHdG}$ was higher in rats fed the AC diets, but not the Non-AC + Casein, suggesting a contribution of dietary AGEs to systemic oxidative stress. Similar to our findings of accelerated kidney disease with autoclave-induced AGEs in feed, Feng et al. [20] showed in 5/6 nephrectomy rats that after 13 weeks of a diet high in AGEs, there was a faster decline in kidney function, glomerular hypertrophy, and interstitial fibrosis. Sebeková et al. [18] showed in 5/6 nephrectomy rats that after a 6-week diet high in AGEs (Non-AC standard diet + bread crusts), there was an increase in proteinuria, but no change in GFR. In our study, we did not assess structural kidney changes but found increased creatinine and BUN with the AC diet high in AGEs, and evidence of altered intestinal phosphorus transport as a result of the diet. We also found an acceleration of the time course of CKD-MBD, although phosphorus and FGF23 remained higher in the AC + Casein diet as we have previously shown, and this may have been from an additive effect of AC diet and the higher amount of phosphate additives in the casein diet (online suppl. Table 1) [3]. These results emphasize the need for strict control of diet composition and detailed reporting of diet in scientific publications.

The gastrointestinal tract is an understudied organ in kidney disease. The absorption of dietary AGEs will depend if they are in free form bound to an amino acid, bound to peptides, or to proteins, with an inverse relationship depending on the molecular weight (free > peptide $>$ protein) [21]. While we did not assess the digestion and absorption of dietary AGEs, the plasma AGEs results suggest that the longer the rats were exposed to dietary AGEs, the higher the circulating AGEs. Furthermore, it has been reported that intestinal RAGE expression, the main receptor for AGEs, is higher in rats with diabetes [22]. However, to our knowledge, the expression of RAGE in the intestine of CKD rats has never been explored. We found that the administration of $\mathrm{AC}$ and $\mathrm{AC}+$ Casein led to upregulated gene expression of RAGE in the duodenum and jejunum, even in the rats with normal kidney function. Perhaps the most striking result was the minimal RAGE gene expression in rats fed the Non-AC + Casein, suggesting that the intestinal RAGE expression is only upregulated in the presence of high dietary AGEs. While we expected a higher RAGE gene expression in the $\mathrm{AC}$ rats, the highest expression was in the $\mathrm{AC}+$ Casein rats. Our casein-based diet had a similar concentration of CML to the Non-AC grain-based diet; however, MG concentration was $\sim 1.8 \mathrm{x}$ higher. Xue et al. [23] reported that MG-derived AGEs are recognized by RAGE, inducing its signal transduction and downstream cascade activation, which may explain the high RAGE expression in the AC + Casein rats. We also observed that DUOX2 gene expression was higher in the rats fed the $\mathrm{AC}$ and $\mathrm{AC}+$ Casein, with minimal expression in the rats fed the Non-AC + Casein, regardless of kidney function. The opposite was true for NOX2. DUOX2 is highly expressed in the enterocytes, while NOX2 is expressed in intestinal phagocytes [24], suggesting a higher phagocytic activity possibly conferring an antimicrobial mechanism, as the standard grain-based diet was not AC [25]. The activation of RAGE and downstream pathways by dietary AGEs suggest that AGEs' systemic effects depend not only on the absorbed AGEs but also on the amount locally present in the intestine to stimulate RAGE. Interestingly, in an experimental 
model of hemorrhagic shock, Raman et al. [26] showed that RAGE signaling led to enhanced gastrointestinal permeability. Gastrointestinal permeability is increased in $\mathrm{CKD}$, and it has been mostly associated with urea-dependent and independent enterocyte damage [27]. Thus, RAGE modulation may represent a novel therapeutic pathway to limit gastrointestinal permeability in CKD.

Our study has several limitations. First, this study was a post hoc design that utilized cohorts of animals studied concurrently under similar, but not identical, housing conditions and dissection techniques (online suppl. Table 2). However, all experimental animals were obtained from our $\mathrm{Cy} /+_{\mathrm{IU}}$ animal colony, although differences in location could affect [28]. As the adoption of AC diets was an institution-wide policy, it was not possible to have a Non-AC grain-based diet comparator group at the same institution. Additionally, while we hypothesize that our results are AGEs-mediated, autoclaving could affect other nutrients, including phytate. We only assessed biochemical abnormalities related to CKD-MBD, and we encourage future studies assessing the effect of AC diets on bone and vascular calcification. Finally, the results need replication in other animal models of CKD.

In conclusion, we report a significant impact on the progression of CKD and CKD-MBD with the autoclaving of grain diets. While the economic losses of a parvovirus outbreak in an animal facility may not be minimal, in our opinion it is important to know the effects of the adoption of these diets, particularly if the phenotype of the experimental animal is affected. Our results also support the need for scientific publications to better report diet content and other dietary factors, including autoclaving. This often overlooked component of experimental design may be an underappreciated factor in the increased concern of lack of reproducibility that impedes scientific progress.

\section{Statement of Ethics}

All procedures conducted during this study were approved by the Indiana University School of Medicine and Purdue University Institutional Animal Care and Use Committees.

\section{Disclosure Statement}

A.B. has received honoraria from Amgen. S.M.M. has received grant funding from Amgen, Sanofi, Chugai, and Keryx and scientific advising fees from Amgen. All other authors have no conflicts of interest to declare.

\section{Funding Sources}

A.B. was supported by the National Institutes of Health T32AR065971. KMHG was supported by NIH K01DK102864. S.M.M. has received grant funding from Amgen, Sanofi, Chugai, and Keryx and scientific advising fees from Amgen and is supported by the Veterans Affairs Merit Award BX001471, and NIH R01DK11087103, P30AR072581. Purdue University rat data were from a study partially funded through a Showalter Research Trust award to K.M.H.G. Part of the results in this paper were presented at Kidney Week 2019.

\section{Author Contributions}

A.B., S.M.M., N.X.C., C.V., K.M.H.G., and M.R.A. designed the study; A.B., S.S., K.D.O.N., and C.V. carried out the experiments; W.C. and J.U. analyzed dietary AGEs; A.B. analyzed the data; A.B. and S.M.M. drafted the paper, all authors revised and approved the final version of the manuscript.

\section{Data Sharing}

The data that support the findings of this study are available in OSF at https://doi.org/10.17605/OSF.IO/QNP5A.

\section{References}

1 Palmer SC, Maggo JK, Campbell KL, Craig JC, Johnson DW, Sutanto B, et al. Dietary interventions for adults with chronic kidney disease. Cochrane Database Syst Rev. 2017 Apr; 4:CD011998

2 Carter RL, Lipman NS. Feed and Bedding. In: Weichbrod RH, Thompson GAH, Norton JN, editors. Management of Animal Care and Use Programs in Research, Education, and Testing. Boca Raton; 2018. pp. 639-54.

3 Moe SM, Chen NX, Seifert MF, Sinders RM, Duan D, Chen X, et al. A rat model of chronic kidney disease-mineral bone disorder. Kidney Int. 2009 Jan;75(2):176-84.
4 Moe SM, Radcliffe JS, White KE, Gattone VH 2nd, Seifert MF, Chen X, et al. The pathophysiology of early-stage chronic kidney disease-mineral bone disorder (CKD$\mathrm{MBD})$ and response to phosphate binders in the rat. J Bone Miner Res. 2011 Nov;26(11): 2672-81.

5 Watson J. Unsterilized feed as the apparent cause of a mouse parvovirus outbreak. J Am Assoc Lab Anim Sci. 2013 Jan;52(1): 83-8.

6 Reuter JD, Livingston R, Leblanc M. Management strategies for controlling endemic and seasonal mouse parvovirus infection in a bar- rier facility. Lab Anim (NY). 2011 May;40(5): $145-52$.

7 Zheng F, He C, Cai W, Hattori M, Steffes M, Vlassara H. Prevention of diabetic nephropathy in mice by a diet low in glycoxidation products. Diabetes Metab Res Rev. 2002 MayJun;18(3):224-37.

8 Vorland CJ, Biruete A, Lachcik PJ, Srinivasan S, Chen NX, Moe SM, et al. Kidney Disease Progression Does Not Decrease Intestinal Phosphorus Absorption in a Rat Model of Chronic Kidney Disease-Mineral Bone Disorder. J Bone Miner Res. 2020 Feb;35(2):33342. 
9 Goldberg T, Cai W, Peppa M, Dardaine V, Baliga BS, Uribarri J, et al. Advanced glycoxidation end products in commonly consumed foods. J Am Diet Assoc. 2004 Aug; 104(8): 1287-91.

10 Motulsky HJ, Brown RE. Detecting outliers when fitting data with nonlinear regression - a new method based on robust nonlinear regression and the false discovery rate. BMC Bioinformatics. 2006 Mar;7(1):123.

11 Teodorowicz M, Hendriks WH, Wichers HJ, Savelkoul HF. Immunomodulation by Processed Animal Feed: The Role of Maillard Reaction Products and Advanced Glycation End-Products (AGEs). Front Immunol. 2018 Sep;9:2088.

12 Jure MN, Morse SS, Stark DM. Identification of nonspecific reactions in laboratory rodent specimens tested by Rotazyme rotavirus ELISA. Lab Anim Sci. 1988 Jun;38(3):273-8.

13 Kilkenny C, Browne WJ, Cuthill IC, Emerson $\mathrm{M}$, Altman DG. Improving bioscience research reporting: the ARRIVE guidelines for reporting animal research. J Pharmacol Pharmacother. 2010 Jul;1(2):94-9.

14 Ricci MR, Ulman, E. A. Laboratory Animal Diets: A Critical Part of Your In Vivo Research. Research Diets. Contract No.: 6.

15 Pellizzon MA, Ricci MR. The common use of improper control diets in diet-induced metabolic disease research confounds data interpretation: the fiber factor. Nutr Metab (Lond). 2018 Jan;15(1):3.
16 Tessier FJ, Niquet-Léridon C, Jacolot $\mathrm{P}$, Jouquand C, Genin M, Schmidt AM, et al. Quantitative assessment of organ distribution of dietary protein-bound 13 C-labeled $\mathrm{N}$ (varepsilon)-carboxymethyllysine after a chronic oral exposure in mice. Mol Nutr Food Res. 2016 Nov;60(11):2446-56.

17 He C, Sabol J, Mitsuhashi T, Vlassara H. Dietary glycotoxins: inhibition of reactive products by aminoguanidine facilitates renal clearance and reduces tissue sequestration. Diabetes. 1999 Jun;48(6):1308-15.

18 Sebeková K, Faist V, Hofmann T, Schinzel R, Heidland A. Effects of a diet rich in advanced glycation end products in the rat remnant kidney model. Am J Kidney Dis. 2003 Mar; 41(3 Suppl 1):S48-51.

19 Vlassara H, Striker LJ, Teichberg S, Fuh H, Li YM, Steffes M. Advanced glycation end products induce glomerular sclerosis and albuminuria in normal rats. Proc Natl Acad Sci USA. 1994 Nov;91(24):11704-8.

20 Feng JX, Hou FF, Liang M, Wang GB, Zhang $\mathrm{X}, \mathrm{Li}$ HY, et al. Restricted intake of dietary advanced glycation end products retards renal progression in the remnant kidney model. Kidney Int. 2007 May;71(9):901-11.

21 Snelson M, Coughlan MT. Dietary Advanced Glycation End Products: Digestion, Metabolism and Modulation of Gut Microbial Ecology. Nutrients. 2019 Jan;11(2):E215.
22 Chen P, Zhao J, Gregersen H. Up-regulated expression of advanced glycation end-products and their receptor in the small intestine and colon of diabetic rats. Dig Dis Sci. 2012 Jan;57(1):48-57.

23 Xue J, Ray R, Singer D, Böhme D, Burz DS, Rai $V$, et al. The receptor for advanced glycation end products (RAGE) specifically recognizes methylglyoxal-derived AGEs. Biochemistry. 2014 May;53(20):3327-35.

24 Jones RM, Neish AS. Redox signaling mediated by the gut microbiota. Free Radic Biol Med. 2017 Apr; 105:41-7.

25 Singel KL, Segal BH. NOX2-dependent regulation of inflammation. Clin Sci (Lond). 2016 Apr;130(7):479-90.

26 Raman KG, Sappington PL, Yang R, Levy RM, Prince JM, Liu S, et al. The role of RAGE in the pathogenesis of intestinal barrier dysfunction after hemorrhagic shock. Am J Physiol Gastrointest Liver Physiol. 2006 Oct;291(4): G556-65.

27 Vaziri ND, Zhao YY, Pahl MV. Altered intestinal microbial flora and impaired epithelial barrier structure and function in CKD: the nature, mechanisms, consequences and potential treatment. Nephrol Dial Transplant. 2016 May;31(5):737-46.

28 Nadon NL, Strong R, Miller RA, Nelson J, Javors $\mathrm{M}$, Sharp ZD, et al. Design of aging intervention studies: the NIA interventions testing program. Age (Dordr). 2008 Dec;30(4):18799. 